\section{Commentary: Cooling the brain for elective aortic hemiarch repair}

\author{
Fausto Biancari, $\mathrm{MD}, \mathrm{PhD},{ }^{\mathrm{a}, \mathrm{b}}$ \\ Tatu Juvonen, $\mathrm{MD}, \mathrm{PhD},{ }^{\mathrm{b}, \mathrm{c}}$ and \\ Giuseppe Speziale, $\mathrm{MD}, \mathrm{PhD}^{\mathrm{d}}$
}

Surgical repair of aortic arch diseases is threatened by neurologic complications secondary to interruption of blood flow to the brain. In the seventies, Gshnitzer, ${ }^{1}$ Griepp and colleagues, ${ }^{2}$ and Pierangeli and colleagues ${ }^{3}$ separately demonstrated the feasibility of aortic arch repair using deep hypothermic circulatory arrest. Hypothermia was shown to effectively protect the brain due to the reduced cerebral metabolic demand. Later on, McCullough and colleagues ${ }^{4}$ and Ehrlich and colleagues ${ }^{5}$ performed seminal studies demonstrating in humans and pigs that the safe limit of circulatory arrest at temperatures between $15^{\circ} \mathrm{C}$ and $25^{\circ} \mathrm{C}$ was shorter than 30 minutes. As a consequence, selective antegrade cerebral perfusion has been introduced to prolong the safe period of circulatory arrest during aortic arch repair. ${ }^{6}$ Despite the fact that this technique has been in use for more than 2 decades, the optimal temperature for a safe circulatory arrest is still controversial.

In this issue of the Journal, Seese and colleagues ${ }^{7}$ reported the results of a large study evaluating the impact of nadir temperature for circulatory arrest using antegrade cerebral perfusion in patients who underwent elective aortic hemiarch repair from the Society of Thoracic Surgeons Adult Cardiac Surgery Database. The analysis included 3898 patients treated at 374 centers. After adjusting for potential confounders, the authors demonstrated that the risk of early mortality was lowest after hypothermic circulatory arrest with a nadir temperature of $27^{\circ} \mathrm{C}$ (odds ratio, 0.42 ;

\footnotetext{
From the ${ }^{\mathrm{a} C l i n i c a}$ Montevergine, GVM Care \& Research, Mercogliano, Italy; ${ }^{\mathrm{b}} \mathrm{Heart}$ and Lung Center, Helsinki University Hospital, University of Helsinki, Helsinki, Finland; ${ }^{~}$ Research Unit of Surgery, Anesthesia and Critical Care, University of Oulu, Oulu, Finland; and ${ }^{\mathrm{d}}$ Anthea Hospital, GVM Care \& Research, Bari, Italy.

Disclosures: The authors reported no conflicts of interest.

The Journal policy requires editors and reviewers to disclose conflicts of interest and to decline handling or reviewing manuscripts for which they may have a conflict of interest. The editors and reviewers of this article have no conflicts of interest.

Received for publication Oct 7, 2021; revisions received Oct 7, 2021; accepted for publication Oct 7, 2021; available ahead of print Oct 11, 2021.

Address for reprints: Fausto Biancari, MD, PhD, Clinica Montevergine, GVM Care \& Research, Mercogliano, Italy (E-mail: faustobiancari@yahoo.it).

J Thorac Cardiovasc Surg 2023;165:1774-5

$0022-5223 / \$ 36.00$

Copyright (c) 2021 by The American Association for Thoracic Surgery

https://doi.org/10.1016/j.jtcvs.2021.10.007
}

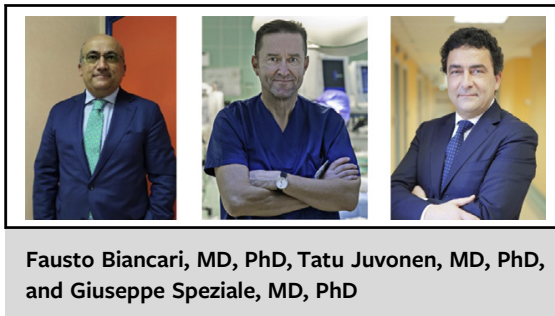

CENTRAL MESSAGE

Mild hypothermia seems to be associated with low risk of early mortality in patients undergoing elective aortic hemiarch repair when circulatory arrest time and procedure duration are short.

95\% confidence interval, 0.42-0.91) and greatest with a nadir temperature of $21^{\circ} \mathrm{C}$ (odds ratio, $1.4 ; 95 \%$ confidence interval, 1.13-1.73).

The authors used sophisticated methods to adjust the outcomes for baseline characteristics, operative variables, as well as hospital volume and individual surgeons. However, potential bias may still exist due to significant differences between the study groups. In the overall series, the nadir temperature of circulatory arrest decreased along with increasing duration of circulatory arrest and aortic crossclamp times. When the authors compared patients who underwent circulatory arrest with a nadir temperature $\leq 20^{\circ} \mathrm{C}$ and those with a nadir temperature $>27.5^{\circ} \mathrm{C}$, those in the deep hypothermic circulatory arrest group had longer aortic crossclamp time (132 vs 101 minutes) and circulatory arrest time (26 vs 16 minutes) despite comparable extent of aortic arch repair and proportion of aortic valve/aortic root procedures. Since deep hypothermia is needed when prolonged circulatory arrest is expected, ${ }^{5}$ it is likely that surgeons and anesthesiologists wisely chose their cerebral protection strategy according to the complexity of the procedure and their experience. Indeed, this study showed that the nadir temperature of circulatory arrest did not have any significant impact on neurologic complications. The present analysis does not include data on antegrade brain perfusion strategy and its duration. Furthermore, multilevel models would have provided important insights on the impact of hospital and individual surgeon on these results. In the light of these findings, in patients undergoing elective aortic hemiarch repair, mild hypothermia seems to be associated 
with low risk of early mortality when circulatory arrest time and the duration of the procedure are short. The optimal nadir temperature for circulatory arrest remains unclear when longer and complex aortic arch procedures are anticipated.

\section{References}

1. Gschnitzer F. Resection of a syphilitic aneurysm of the aortic arch by left heart bypass, profound hypothermia, and circulatory arrest. Thoraxchir Vask Chir. 1973;21:87-90.

2. Griepp RB, Stinson EB, Hollingsworth JF, Buehler D. Prosthetic replacement of the aortic arch. J Thorac Cardiovasc Surg. 1975;70:1051-63.
3. Pierangeli A, Coli G, Donati A, Galli R, Mikus P, Turinetto B. Treatment of aortic arch aneurysms with deep hypothermia and circulatory arrest. J Cardiovasc Surg (Torino). 1975;16:409-14.

4. McCullough JN, Zhang N, Reich DL, Juvonen TS, Klein JJ, Spielvogel D, et al. Cerebral metabolic suppression during hypothermic circulatory arrest in humans. Ann Thorac Surg. 1999;67:1895-9.

5. Ehrlich MP, McCullough JN, Zhang N, Weisz DJ, Juvonen T, Bodian CA, et al. Effect of hypothermia on cerebral blood flow and metabolism in the pig. Ann Thorac Surg. 2002;73:191-7.

6. Di Bartolomeo R, Pacini D, Di Eusanio M, Pierangeli A. Antegrade selective cerebral perfusion during operations on the thoracic aorta: our experience. Ann Thorac Surg. 2000;70:10-5.

7. Seese L, Chen EP, Badhwar V, Thibault D, Habib RH, Jacobs J, et al. Optimal circulatory arrest temperature for aortic hemiarch replacement with antegrade brain perfusion. J Thorac Cardiovasc Surg. 2023;165:1759-70.e3. 